University of Nebraska - Lincoln

DigitalCommons@University of Nebraska - Lincoln

Faculty Papers and Publications in Animal

Science

Animal Science Department

February 2004

Genetic relationships between sex-specific traits in beef cattle:

Mature weight, weight adjusted for body condition score, height and body condition score of cows, and carcass traits of their steer relatives

\author{
K. A. Nephawe \\ University of Nebraska-Lincoln \\ L. V. Cundiff \\ USDA, ARS, Roman L. Hruska U.S. Meat Animal Research Center
}

M. E. Dikeman

Kansas State University, Manhattan

J. D. Crouse

National Swine Research Information Center, USDA-ARS, Ames, IA

L. Dale Van Vleck

University of Nebraska-Lincoln, dvan-vleck1@unl.edu

Follow this and additional works at: https://digitalcommons.unl.edu/animalscifacpub

Part of the Animal Sciences Commons

Nephawe, K. A.; Cundiff, L. V.; Dikeman, M. E.; Crouse, J. D.; and Van Vleck, L. Dale, "Genetic relationships between sex-specific traits in beef cattle: Mature weight, weight adjusted for body condition score, height and body condition score of cows, and carcass traits of their steer relatives" (2004). Faculty Papers and Publications in Animal Science. 205.

https://digitalcommons.unl.edu/animalscifacpub/205

This Article is brought to you for free and open access by the Animal Science Department at DigitalCommons@University of Nebraska - Lincoln. It has been accepted for inclusion in Faculty Papers and Publications in Animal Science by an authorized administrator of DigitalCommons@University of Nebraska - Lincoln. 


\title{
Genetic relationships between sex-specific traits in beef cattle: Mature weight, weight adjusted for body condition score, height and body condition score of cows, and carcass traits of their steer relatives ${ }^{1}$
}

\author{
K. A. Nephawe ${ }^{* 2}$, L. V. Cundiff $\dagger$, M. E. Dikeman $\ddagger$ J. D. Crouse $\S^{3}$, and L. D. Van Vleck $\mathbb{I}^{4}$ \\ *Department of Animal Science, University of Nebraska, Lincoln 68583-0908; USDA, ARS, \\ Roman L. Hruska U.S. Meat Animal Research Center, †Clay Center, NE 68933 and ILincoln, NE 68583-0908; \\ $\ddagger$ Department of Animal Science and Industry, Kansas State University, Manhattan 66506-0201; and \\ §National Swine Research Information Center, USDA-ARS, Ames, IA 50011
}

\begin{abstract}
Data from the first four cycles of the Germplasm Evaluation Program at the U.S. Meat Animal Research Center (USMARC) were used to investigate genetic relationships between mature weight (MW, $\mathrm{n}=37,710$ ), mature weight adjusted for body condition score (AMW, $\mathrm{n}=37,676$ ), mature height (HT, $\mathrm{n}=37,123)$, and BCS $(\mathrm{n}=37,676)$ from 4- to 8-yr old cows $(n=1,800)$ and carcass traits $(n=4,027)$ measured on their crossbred paternal half-sib steers. Covariance components among traits were estimated using REML. Carcass traits were adjusted for age at slaughter. Estimates of heritability for hot carcass weight (HCWT); percentage of retail product; percentage of fat; percentage of bone; longissimus muscle area; fat thickness adjusted visually; estimated kidney, pelvic, and heart fat percentage; marbling score; Warner-Bratzler shear force; and taste panel tenderness measured on steers were moderate to high ( 0.26 to 0.65$)$, suggesting that
\end{abstract}

selection for carcass and meat traits could be effective. Estimates of heritability for taste panel flavor and taste panel juiciness were low and negligible $(0.05$ and 0.01 , respectively). Estimates of heritability from cow data over all ages and seasons were high for MW, AMW, and HT $(0.52,0.57,0.71$; respectively) and relatively low for BCS (0.16). Pairwise analyses for each female mature trait with each carcass trait were done with bivariate animal models. Estimates of genetic correlations between cow mature size and carcass composition or meat quality traits, with the exception of HCWT, were relatively low. Selection for cow mature size (weight and/or height) could be effective and would not be expected to result in much, if any, correlated changes in carcass and meat composition traits. However, genetic correlations of cow traits, with the possible exception of BCS, with HCWT may be too large to ignore. Selection for steers with greater HCWT would lead to larger cows.

Key Words: Genetic Correlation, Growth, Heritability, Meat Composition

(C2004 American Society of Animal Science. All rights reserved.

J. Anim. Sci. 2004. 82:647-653

\section{Introduction}

Breeding objectives for beef cattle have evolved over the years to meet production standards, resources, consumer demands, and marketing practices. Because the current trend in the beef industry is to focus not only on growth and maternal traits, but also on carcass and

\footnotetext{
${ }^{1}$ Published as paper No. 14148, Journal Ser., Nebraska Agric. Res. Div., Univ. of Nebraska, Lincoln 68583-0908.

${ }^{2}$ Current address: Agricultural Research Council of South Africa, Animal Improvement Institute, P/Bag X2, Irene, 0062, South Africa. ${ }^{3} 2150$ Pammel Drive.

${ }^{4}$ Correspondence: A218 Animal Sciences (phone: 402-472-6010; fax: 402-472-6362; e-mail: lvanvleck@unlnotes.unl.edu).

Received June 23, 2003.

Accepted November 3, 2003.
}

meat composition, reliable estimates of genetic correlations are needed to determine whether improvement in one or more traits would compromise improvement in the others and also to design economic indexes to maximize economic gain. For example, as producers have tried to improve such traits as overall growth (e.g., weaning and slaughter weight), both breeders and scientists have debated whether mature cow size is being increased beyond levels required for optimum economic returns. Worrisome for cattlemen are high maintenance costs associated with large mature cows (Fiss and Wilton, 1992). If breeders were to select for optimal mature cow size, knowledge of genetic relationships between mature size and other economically important traits, most importantly carcass traits, would be needed to improve more efficiently both female productivity and carcass composition. 
The primary objective of this study was to estimate the genetic correlations between traits associated with mature body size (weight, height, and body condition score) measured on cows and carcass traits measured on their steer relatives. Although numerous estimates of genetic relationships for many pairs of growth and carcass traits and for one trait measured on females and the other on males (reviews by Mohiuddin, 1993; Koots et al., 1994a,b) are available, information on how mature size of cows is related to carcass traits is scarce. Since carcass traits are difficult and expensive to measure, a reliable indirect method to select for them would be welcomed by the beef industry. The results of previous studies (MacNeil et al., 1984; Splan et al., 2002) suggest that weaning weight is not an effective indicator.

\section{Materials and Methods}

\section{Data}

Data from the first four cycles of the Germplasm Evaluation Program (GPE), at the U.S. Meat Animal Research Center (USMARC), Clay Center, NE, were used. The primary objective of the GPE was to understand the optimization of biological factors, such as mature size, growth rate, maturing rate, milk production, body composition, and other traits relating to economic beef production, in various production situations (Gregory et al., 1978). The program began in 1969 and has been conducted in several cycles. The first four cycles are considered in this study. Detailed information about the design of the experiment and the breeding plans have been reported by Gregory et al. (1978), Koch et al. (1982), and Cundiff et al. (1998).

\section{Data Collected on Steers}

Details of postweaning management of steers and serial slaughter protocol were presented by Koch et al. (1976, 1979, 1982) and Wheeler et al. (1996). At slaughter, hot carcass weight (HCWT) was recorded for each steer. After a 24-h chill, carcasses were evaluated for marbling (MARB); longissimus muscle area (LMA); estimated kidney, pelvic, heart fat percentage (KPH); and adjusted fat thickness (AFAT). A visual estimate of kidney, pelvic, and heart fat $(\mathrm{KPH})$ was made and converted to a percentage of total carcass weight. Fat thickness measured over the rib eye at the 12 th rib was adjusted (AFAT) by visually considering fat thickness over other cuts, e.g., round or chuck. Measurements of fat thickness were also adjusted for damage done by pulled hides, as the removal of hide from a carcass often distorts the subcutaneous layer of fat. Marbling was scored on a 100-point scale within each of seven categories. The conversion of marbling scores to numeric scores can be found in Nephawe (2003). In the first three cycles of the GPE (1970 through 1976), the right side of each carcass was transported to Kansas
State University, Manhattan, for processing. In Cycle IV (1986 to 1990), processing was done in the meat laboratory at the USMARC, Clay Center, NE. The carcass side was separated into wholesale cuts and processed into boneless, closely trimmed retail cuts, fat trim, and bone. Weights of retail product (RPP), fat trim (FAT), and bone (BONE), were determined for each wholesale cut and were expressed as percentages of actual carcass weight. Steaks removed from the longissimus dorsi muscle were frozen and later thawed and prepared for Warner-Bratzler shear force (WBSF) determination of tenderness and for taste panel evaluation. The panel scored cooked steak cores for tenderness (TPT), juiciness (TPJ), and beef flavor intensity (TPF). Evaluations at Kansas State University were based on a 9 -point scale ( 1 = extremely tough, dry, or bland; $9=$ extremely tender, juicy, or flavorful), whereas taste panels at USMARC used an 8-point scale ( $8=$ extremely tender, juicy, or intense; 1 = extremely tough, dry, or bland). Summary statistics and variance components for carcass traits are presented in Table 1.

\section{Data Collected on Cows}

Although the literature describes an almost unlimited range of procedures by which mature body size can be measured, the present study considered only individual measurements taken on cows that were $4 \mathrm{yr}$ of age or older. All cows ( $n=1,800)$ were weighed, measured for hip height and visually scored for body condition four times each year: 1) spring (mid May) at start of breeding season, 2) summer (early August) at the end of the breeding season, 3) fall (late October) at rectal palpation for pregnancy following weaning, and 4) winter (early February) before calving. These measurements have been described (MacNeil et al., 1984) as being taken 60 to 90,100 to 140 , and $200 \mathrm{~d}$ after calving and $60 \mathrm{~d}$ before calving, respectively. Body condition score was based on a subjective classification scale of nine points based on the Guidelines for Uniform Beef Improvement Programs (BIF, 1996). Details of postweaning management of females and mating plans can be found in Laster et al. (1976, 1979), Gregory et al. (1979), and Thallman et al. (1999). The number of records and the unadjusted means and standard deviations for mature weight (MW), weight adjusted for condition score (AMW), height (HT) and body condition score $(\mathbf{C S})$ are presented in Table 2.

\section{Statistical Analyses}

Preliminary analyses were performed using mixed model procedures of SAS (Littell et al., 1996) to determine which systematic effects to include in the model for estimating (co)variance components for MW, AMW, HT, and CS and each of the carcass traits. The final sets of systematic effects that were found to be significant $(P$ $<0.01$ ) and therefore included in the models for estimation of variance components for all carcass traits were 
Table 1. Summary statistics and estimates of variance components and genetic parameters $\left( \pm\right.$ SE) for carcass traits ${ }^{a, b, c}$

\begin{tabular}{lccccc}
\hline \hline Trait $^{\mathrm{d}}$ & No. & Mean $\pm \mathrm{SD}$ & $\mathrm{h}^{2}$ & $\mathrm{~d}^{2}$ & $\mathrm{e}^{2}$ \\
\hline HCWT, kg & 4,027 & $311.32 \pm 41.19$ & $0.52 \pm 0.05$ & $0.07 \pm 0.03$ & $0.41 \pm 0.05$ \\
RPP, \% & 3,650 & $68.73 \pm 4.09$ & $0.59 \pm 0.07$ & $0.05 \pm 0.03$ & $0.36 \pm 0.06$ \\
FAT, \% & 3,650 & $18.39 \pm 4.71$ & $0.53 \pm 0.07$ & $0.06 \pm 0.03$ & $0.41 \pm 0.05$ \\
BONE, \% & 3,651 & $12.89 \pm 1.09$ & $0.52 \pm 0.07$ & $0.00 \pm 0.03$ & $0.48 \pm 0.06$ \\
LMA, cm & 4,031 & $73.43 \pm 9.02$ & $0.57 \pm 0.07$ & $0.00 \pm 0.03$ & $0.43 \pm 0.05$ \\
AFAT, cm & 3,628 & $1.22 \pm 0.49$ & $0.46 \pm 0.07$ & $0.03 \pm 0.03$ & $0.50 \pm 0.05$ \\
KPH, \% & 3,651 & $3.95 \pm 1.14$ & $0.65 \pm 0.07$ & $0.00 \pm 0.03$ & $0.35 \pm 0.06$ \\
MARB, score & 4,015 & $5.32 \pm 1.04$ & $0.46 \pm 0.06$ & $0.00 \pm 0.03$ & $0.54 \pm 0.05$ \\
WBSF, kg & 3,652 & $4.17 \pm 1.55$ & $0.29 \pm 0.06$ & $0.00 \pm 0.03$ & $0.71 \pm 0.05$ \\
TPF, score & 2,360 & $6.10 \pm 1.33$ & $0.05 \pm 0.06$ & $0.02 \pm 0.04$ & $0.93 \pm 0.06$ \\
TPJ, score & 2,360 & $6.13 \pm 1.17$ & $0.01 \pm 0.06$ & $0.00 \pm 0.04$ & $0.99 \pm 0.06$ \\
TPT, score & 2,360 & $5.93 \pm 1.47$ & $0.26 \pm 0.08$ & $0.00 \pm 0.04$ & $0.74 \pm 0.07$ \\
\hline
\end{tabular}

${ }^{\mathrm{a}}$ No. $=$ number of records; Mean = unadjusted mean.

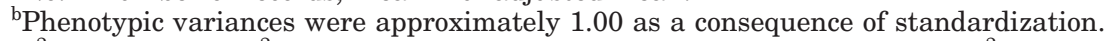

${ }^{c} \mathrm{~h}^{2}=$ heritability; $\mathrm{d}^{2}=$ fraction of total variance due to effects of the dam; $\mathrm{e}^{2}=$ fraction of total variance due to temporary environmental effects.

${ }^{\mathrm{d}} \mathrm{HCWT}=$ hot carcass weight; $\mathrm{RPP}=$ percentage of retail product; $\mathrm{FAT}=$ fat percent, $\mathrm{BONE}$ = bone percent; LMA = longissimus muscle area; AFAT = adjusted fat thickness; KPH = estimated percentage of kidney, pelvic, and heart; MARB = marbling score $(3=$ traces, $9=$ moderately abundant $)$; WBSF $=$ Warner-Bratzler shear force; TPF $=$ taste panel flavor $(1=$ worst, $9=$ best $)$; TPJ = taste panel juiciness $(1=$ worst, $9=$ best $)$; TPT $=$ taste panel tenderness $(1=$ worst, 9 = best $)$.

breed group (or line), birth year, and their interactions; age of dam (2, 3, 4 yr and older); and linear covariates of weaning age and slaughter age in days. Because carcass data were collected at two locations, data were standardized with the phenotypic standard deviation for each year to account for some differences in scales of measurement. Because of the large number of breed groups and relatively few steers and cows per breed group, homogeneity of variance was assumed for carcass and cow traits.

Fixed factors that were significant sources of variation for MW and CS included cow breed group (or line), age of the cow in years, season of measurement and their interactions, year of birth, and the cow's physiological status (pregnancy-lactation code). The same fixed effects were also included in the model for HT except that the cow's physiological status was excluded. Analysis of adjusted MW included body condition score as a linear covariate. Three sets of analyses were run for each trait of the cow using repeatability models, assuming that different measurements of a particular trait on the cow are the same trait with constant vari- ances: 1) overall analyses including all data, 2) analyses by age of the cow (in years) when measured, and 3) analyses by season of measurement of the cow. Analyses by age of the cow in years included age in days within season of measurement as an additional linear covariate.

Variance components for individual traits were estimated with single-trait animal models. Pairwise analyses of combinations of repeated measures of MW, AMW, $\mathrm{HT}$, and BCS with each carcass trait were performed using bivariate animal models. All analyses were performed with a derivative-free REML algorithm (Smith and Graser, 1986) using the MTDFREML programs (Boldman et al., 1995). The univariate analysis of each carcass trait, in addition to the fixed effects described above, included additive genetic and total effect due to the dam of the animal as random effects in the model. Total effect due to the dam, included as an additional uncorrelated random effect, accounted jointly for maternal genetic and permanent environmental effects of the dam. Additive genetic and permanent environmental effects of the cow were included as random effects in

Table 2. Summary statistics and estimates of variance components and genetic parameters for mature weight (MW), mature weight adjusted for body condition score (AMW), mature height (HT), and body condition score (CS) of $\operatorname{cows}^{\mathrm{a}, \mathrm{b}}$

\begin{tabular}{lccrccc}
\hline \hline & No. & Mean \pm SD & \multicolumn{1}{c}{$\sigma_{\mathrm{p}}^{2}$} & \multicolumn{1}{c}{$\mathrm{h}^{2}$} & \multicolumn{1}{c}{$\mathrm{c}^{2}$} & $\mathrm{e}^{2}$ \\
\hline MW, kg & 37,710 & $526 \pm 69.3$ & $2,788.26$ & $0.52 \pm 0.04$ & $0.20 \pm 0.04$ & $0.28 \pm 0.01$ \\
AMW, kg & 37,676 & $526 \pm 69.3$ & $2,231.41$ & $0.57 \pm 0.04$ & $0.15 \pm 0.04$ & $0.28 \pm 0.01$ \\
HT, cm & 37,123 & $128 \pm 6.2$ & 15.76 & $0.71 \pm 0.05$ & $0.08 \pm 0.04$ & $0.22 \pm 0.01$ \\
CS, point & 37,676 & $6.4 \pm 1.02$ & 0.81 & $0.16 \pm 0.02$ & $0.19 \pm 0.02$ & $0.65 \pm 0.01$ \\
\hline
\end{tabular}

\footnotetext{
${ }^{\mathrm{a}}$ No. $=$ number of records; Mean = unadjusted mean.

${ }^{\mathrm{b}} \sigma_{\mathrm{p}}^{2}=$ phenotypic variance; $\mathrm{h}^{2}=$ heritability; $\mathrm{c}^{2}=$ fraction of total variance due to animal permanent environmental effects; $\mathrm{e}^{2}=$ fraction of total variance due to temporary environmental effects.
} 
models for measurements of cow mature size. Maternal genetic effects were found to be negligible and were excluded from models for mature cow size.

The equation of the general linear model for bivariate analysis is

$$
\begin{aligned}
{\left[\begin{array}{l}
\mathbf{y}_{1} \\
\mathbf{y}_{2}
\end{array}\right]=} & {\left[\begin{array}{ll}
\mathbf{X}_{1} & 0 \\
0 & \mathbf{X}_{2}
\end{array}\right]\left[\begin{array}{l}
\beta_{1} \\
\beta_{2}
\end{array}\right]+\left[\begin{array}{ll}
\mathbf{z}_{1} & 0 \\
0 & \mathbf{Z}_{2}
\end{array}\right]\left[\begin{array}{l}
\mathbf{u}_{1} \\
\mathbf{u}_{2}
\end{array}\right] } \\
& +\left[\begin{array}{ll}
\mathbf{S}_{1} & 0 \\
0 & \mathbf{S}_{2}
\end{array}\right]\left[\begin{array}{l}
\mathbf{p e}_{1} \\
\mathbf{p e}_{2}
\end{array}\right]+\left[\begin{array}{l}
\mathbf{e}_{1} \\
\mathbf{e}_{2}
\end{array}\right]
\end{aligned}
$$

where $\mathbf{y}_{\mathbf{i}}$ represents the vector of measurements for Trait $\mathbf{i}$ (where 1 and 2 represent traits of the cows and steers, respectively), the $\boldsymbol{\beta}_{\mathbf{i}}$ are the associated vectors of fixed effects, the $\mathbf{u}_{\mathbf{i}}$ are the vectors of random effects associated with the additive genetic effects of the animals, the $\mathbf{p e}_{\mathbf{i}}$ are the vectors of random effects associated with the permanent environmental effects of animals (Trait 1) and total effect of dams (Trait 2), respectively, and the $\mathbf{e}_{\mathbf{i}}$ are the vectors of residual effects for Trait 1 and Trait 2, respectively. The design matrices, $\mathbf{X}_{\mathbf{i}}, \mathbf{Z}_{\mathbf{i}}$, and $\mathbf{S}_{\mathbf{i}}$, are known incidence matrices relating observations to fixed and random effects.

The (co)variance structure for the random effects is

$$
\operatorname{var}\left[\begin{array}{l}
\mathbf{u}_{\mathbf{1}} \\
\mathbf{u}_{\mathbf{2}} \\
\mathbf{p e}_{\mathbf{1}} \\
\mathbf{p e}_{\mathbf{2}} \\
\mathbf{e}_{\mathbf{1}} \\
\mathbf{e}_{\mathbf{2}}
\end{array}\right]=\left[\begin{array}{llllll}
\mathrm{g}_{11} \mathbf{A} & \mathrm{g}_{12} \mathbf{A} & 0 & 0 & 0 & 0 \\
\mathrm{~g}_{21} \mathbf{A} & \mathrm{g}_{22} \mathbf{A} & 0 & 0 & 0 & 0 \\
0 & 0 & \mathbf{I} \mathbf{q}_{11} & 0 & 0 & 0 \\
0 & 0 & 0 & \mathbf{I q}_{22} & 0 & 0 \\
0 & 0 & 0 & 0 & \mathbf{I r}_{11} & 0 \\
0 & 0 & 0 & 0 & 0 & \mathbf{I r}_{22}
\end{array}\right]
$$

where $\mathbf{A}$ is the numerator relationship matrix, $g_{11}$ and $\mathrm{g}_{22}$ are the additive genetic variances for Traits 1 and $2, \mathrm{~g}_{12}=\mathrm{g}_{21}$ is the additive genetic covariance between Trait 1 and $2, q_{11}$ is the permanent environmental variance for Trait $1, q_{22}$ is the total maternal effect variance for Trait 2, the I's are identity matrices of appropriate orders, and $r_{11}$ and $r_{22}$ are residual variances for Traits 1 and 2, respectively.

Local convergence was declared when the variance of the simplex was less than $10^{-6}$, after which several restarts were made until convergence at global maximum was declared when -2(log likelihood) did not change to the second decimal. Approximate standard errors for estimates of genetic parameters for singletrait analyses were estimated using the average information matrix (Johnson and Thompson, 1995) and the "delta" method as implemented by Dodenhoff et al. (1998). With two-trait analyses, MTDFREML is able to estimate parameters for bivariate models but the package does not calculate the approximate sampling variances for the estimated (co)variances unless the two traits are measured on all animals. Because cow traits and carcass traits were measured on distinct subsets of animals, standard errors for estimates of genetic correlations in bivariate models were calculated by reparameterizing to an equivalent single-trait animal model (S. D. Kachman, personal communication) as described by Nephawe (2003).

\section{Results and Discussion}

\section{Carcass Traits}

Estimates of genetic parameters and standard errors for carcass traits are presented in Table 1. Estimates of heritability for carcass and meat composition were moderate to high, with the exception of TPJ and TPF, which had estimates that were small and not significantly different from zero. Moderate to high estimates of heritability are indicative that selection would be effective. The proportions of variance due to total maternal effects were small with most estimates near 0.00 . The only true nonzero estimate was for HCWT at 0.07 .

Genetic parameters (heritabilities and correlations) among carcass traits from designed experiments and from field data (mostly with limited numbers) are available in the literature (Koots et al., 1994a,b). Although estimates of heritability in this study were generally consistent with those reported in the literature for ageconstant analyses, many of the previous studies (e.g., Koch et al., 1982; Splan et al., 2002) used subsets of this data set, and therefore comparisons are not of independent analyses. The estimate of heritability for HCWT (0.52) is similar to the unweighted average of estimates of 0.45 reported by Koots et al. (1994a). The estimate of heritability for RPP (0.59) agrees with 0.58 reported by Koch et al. (1982) but is slightly higher than 0.45 reported by MacNeil et al. (1984).

The moderate estimate of heritability for FAT (0.53) is slightly higher than 0.45 reported by Gregory et al. (1995) and slightly lower than 0.57 reported by Koch et al. (1982). Gregory et al. (1995) and Koch et al. (1982), respectively, reported estimates of heritability for BONE of 0.43 and 0.53 , which are in agreement with the estimate from the current study (0.52). The estimate of heritability for LMA (0.57) is similar to the weighted average estimate (0.42) from 16 studies reported by Koots et al. (1994a).

Estimate of heritability for AFAT (0.46) is comparable with estimates of 0.43 and 0.46 reported by Koots et al. (1994a) and Pariacote et al. (1998). Although high, the estimate of heritability for KPH (0.65) is less than the 0.83 obtained by Koch et al. (1982), but larger than the value of 0.43 obtained by Pariacote et al. (1998). The estimate of heritability for MARB (0.46) confirms literature reports that marbling may be changed by selection. Literature estimates have a wide range, from 0.23 by Woodward et al. (1992) to 0.88 by Pariacote et al. (1998).

Selection for reduced shear force should be effective for improving beef tenderness as indicated by the magnitude of the estimate of heritability (0.29) for WBSF as a measure of tenderness. Koots et al. (1994a) re- 
viewed 13 studies and reported a similar weighted average of estimates of heritability for WBSF, although with fewer data and very large standard errors (both individually and as a weighted mean) as compared to the present study.

The estimate of heritability for TPT (0.29) was slightly higher than the 0.23 reported by Wilson et al. (1976). Most of previous research (e.g., Van Vleck et al., 1992) indicated that selection for TPJ and TPF would result in little, if any, genetic progress. The estimates of heritability for TPF $(0.05 \pm 0.06)$ and TPJ $(0.01 \pm$ $0.06)$ from this study cast doubt on whether these traits are under much or any additive genetic control. Because of the small estimates of heritability, TBF and TPJ were excluded from analyses with cow traits.

\section{Cow Traits}

Estimates of variance components and genetic parameters for MW, AMW, HT and CS from analyses with overall cow data are presented in Table 2. Estimates by age of cow or by season were similar to the overall estimates, although repeatability for CS was greater within an age class than within a season class. In general, estimates of heritability were high for MW (0.52), AMW (0.57), and for HT (0.71) and relatively low for CS (0.16). The proportion of phenotypic variance due to permanent environmental effects associated with the cow accounted for $0.20,0.15,0.08$, and 0.19 of the phenotypic variance for MW, AMW, HT, and CS, respectively. Mature weight, AMW, and HT are highly repeatable traits as indicated by the magnitude of total animal variance as proportions of total phenotypic variance $(0.72,0.72$, and 0.79 , respectively). The fraction of total variance due to animal effects was lower (0.35) for CS. In general, estimates of heritability are in agreement with estimates from the review of Koots et al. (1994a).

The literature reveals that measures of mature weight of cows are influenced by body condition score (Morrow and Marlowe, 1966). In the present study, adjusting MW for CS reduced the phenotypic variance $\left(2,231\right.$ vs. $\left.2,788 \mathrm{~kg}^{2}\right)$, but increased the fraction of variance due to additive genetic effects (0.57 vs. 0.52$)$ at the expense of the fraction of variance due to permanent environmental effects ( 0.15 vs. 0.20$)$. Johnston et al. (1996) and Choy et al. (2002) also observed the same trend when adjusting mature weight by body condition scores; however, whether mature weight should be adjusted for body condition score is arguable. For adjusted weights to be useful for national cattle evaluation, data must be available. Body condition scores are not routinely available in field records. Furthermore, body condition scores are measured subjectively and have lower repeatability than weight and height measures.

The usual trend among published estimates is that cow height is more heritable than cow weight. The present study follows the same trend in that the estimate of heritability for HT (0.71) is considerably larger than the corresponding estimate for cow weight whether ad- justed or unadjusted for CS (Table 2). Literature estimates of heritability for cow hip height include 0.62 by Choy et al. (2002) and 0.83 by Northcutt and Wilson (1993).

The estimate of heritability for body condition score (0.16) obtained in this study (Table 2) is well within the range of published estimates. Literature estimates of heritability for body condition scores are in the range of 0.11 to 0.21 (Johnston et al., 1996; Choy et al., 2002). Although an intermediate body condition score may be optimum, genetic progress from direct selection on body condition score might be slow due to low heritability. Instead, body condition score may be more useful for nutritional management.

Estimates of genetic parameters by season of measurement and by age of measurement of the cow can be found in Nephawe (2003). Estimates were relatively consistent with estimates from all the data. Repeated measurement of cow weight and height may be of little practical importance. A practical strategy for a cattle producer may be to take hip height, body weight, and condition score measurements annually at weaning time so that mature weight adjusted for condition score could be calculated if desired.

\section{Genetic Correlations Between Sex-Specific Traits}

Estimates of genetic correlations and standard errors from pair-wise analyses of MW, AMW, CS and HT of cows with carcass traits measured on steers are presented in Table 3. In general, estimates of genetic correlations between carcass traits of steers and MW of cows were similar whether MW was adjusted or unadjusted for CS. The high positive genetic correlation between cow weight and HCWT of steers (0.81) was expected because steers were slaughtered after attaining most of their adult/mature body weight. Both HCWT and cow weight, like most weight traits, have intermediate optimums. With purebred or rotational crossing systems, reduction in cow weights without taking HCWT into consideration, might increase the percentage of carcasses weighing less than a minimum target weight of, say, $250 \mathrm{~kg}$. Given the discounts presently applied to carcasses that are too heavy and especially those that are too light, the latter change would be economically important.

Estimates of genetic correlations between mature weight and RPP, FAT, and AFAT were slightly negative $(-0.05,-0.02$, and -0.03 ; respectively) and not significantly different from zero. Low to moderate estimates of genetic correlations between mature weight and BONE (0.25) and LMA (0.34) indicate that sires selected on the basis of producing females that are smaller at maturity would be expected to produce steers with less percentage of bone and smaller longissimus muscle area. Because beef producers may desire to increase LMA, the positive genetic association of mature weight and LMA would be considered somewhat antagonistic although the magnitude of the antagonism is not great. 
Table 3. Estimates of genetic correlations ( \pm SE) from two-trait analyses of carcass traits of steers and repeated measurements of mature weight (MW), mature weight adjusted for condition score (AMW), height (HT), and body condition score (CS) of cows ${ }^{\mathrm{a}}$

\begin{tabular}{lrrrr}
\hline \hline & \multicolumn{1}{c}{ MW, kg } & AMW, kg & HT, cm & \multicolumn{1}{c}{ CS, score } \\
\hline HCWT, kg & $0.81 \pm 0.06$ & $0.82 \pm 0.05$ & $0.69 \pm 0.06$ & $0.23 \pm 0.09$ \\
RPP, \% & $-0.05 \pm 0.07$ & $-0.02 \pm 0.07$ & $0.03 \pm 0.07$ & $-0.12 \pm 0.09$ \\
FAT, \% & $-0.02 \pm 0.08$ & $-0.07 \pm 0.07$ & $-0.16 \pm 0.07$ & $0.20 \pm 0.09$ \\
BONE, \% & $0.25 \pm 0.08$ & $0.34 \pm 0.07$ & $0.48 \pm 0.07$ & $-0.38 \pm 0.09$ \\
LMA, cm & $0.34 \pm 0.07$ & $0.32 \pm 0.07$ & $0.25 \pm 0.07$ & $0.24 \pm 0.09$ \\
AFAT, cm & $-0.03 \pm 0.08$ & $-0.10 \pm 0.08$ & $-0.16 \pm 0.07$ & $0.30 \pm 0.09$ \\
KPH, \% & $0.00 \pm 0.07$ & $-0.02 \pm 0.07$ & $-0.07 \pm 0.06$ & $0.06 \pm 0.09$ \\
MARB, score & $-0.15 \pm 0.08$ & $-0.16 \pm 0.08$ & $-0.17 \pm 0.07$ & $-0.03 \pm 0.10$ \\
WBSF, kg & $0.15 \pm 0.10$ & $0.15 \pm 0.09$ & $0.22 \pm 0.09$ & $0.08 \pm 0.12$ \\
TPT, score & $-0.20 \pm 0.12$ & $-0.20 \pm 0.12$ & $-0.25 \pm 0.11$ & $-0.08 \pm 0.15$ \\
\hline
\end{tabular}

${ }^{\mathrm{a}} \mathrm{HCWT}=$ hot carcass weight; $\mathrm{RPP}=$ percentage of retail product; $\mathrm{FAT}=$ fat percent; $\mathrm{BONE}=$ bone percent; LMA = LM area; AFA = adjusted fat thickness; KPH = estimated percentage of kidney, pelvic, and heart; $\mathrm{MARB}=$ marbling score $(3=$ traces, $9=$ moderately abundant $)$; WSF $=$ Warner-Bratzler shear force; $\mathrm{TPT}=$ taste panel tenderness $(1=$ worst, $9=$ best $)$.

Estimates of genetic correlations between mature weight measurements of cows and MARB (-0.15), WBSF (0.15), and TPT $(-0.20)$ are small. If beef cattle producers wanted to reduce mature size of their cow herds, selection for cows of smaller mature sizes would tend to slowly increase marbling and tenderness in steers. Genetic associations of mature weight with TPF and TPJ were not estimated because the proportion of total variance due to additive genetic variance for TPF and TPJ was negligible (Table 1).

Information on relationships between mature weight and carcass traits is scarce. MacNeil et al. (1984) obtained a low negative estimate of genetic correlation $(-0.09)$ between mature weight and fat-trim weight on an age-constant basis. Speer (1993) reported a high negative correlation $(-0.54)$ between the mature weight of cows ( $\mathrm{n}=690)$ and fat thickness of bulls and steers $(\mathrm{n}=875)$ slaughtered on a weight-constant basis. They concluded that females from sires selected for reduced fat trim of steer progeny would be larger at maturity. Cundiff et al. (1969) reported that, on a weight constant basis, if selection pressure for growth were increased, the correlated response would be for leaner carcasses.

An inconsistency between this study and that reported by Speer (1993) was his negative estimate $(-0.18)$ of genetic correlation between mature weight and LMA compared with a positive estimate (0.34) in this study. In the study by Speer, male progeny data (from both bulls and steers) were analyzed at a constant-weight end point. Speer noted that the relationships between carcass traits and mature weight may differ when cattle are slaughtered at a constant age end point. Carcass data (only from steers) were analyzed on an age-constant end point in the current study.

Estimates of genetic correlations between body condition score and carcass traits for overall data are presented in Table 3. Genetic correlations between body condition score and RPP (-0.12), FAT (0.20), BONE $(-0.38)$, AFAT (0.30), WBSF (0.08), and TPT (-0.08) although small to moderate in magnitude may be unfa- vorable because strong selection pressure on improving these carcass traits would tend to result in decreased CS of the other sex. The converse might also be true, although an intermediate CS may be optimum. The magnitudes of the estimated genetic correlations are low, and thus correlated responses on one trait from selection on the other trait would not be expected to be great, whether favorable or unfavorable.

The estimates of genetic correlations for HT with HCWT (0.69) and BONE (0.48) are not unexpected because selection for a skeletal trait in one sex would be expected to change comparable skeletal traits in the opposite sex in the same direction (Table 3). Small but unfavorable estimates of genetic correlations were obtained between height and LMA (0.25), FAT (-0.16), and AFAT (-0.16), respectively. Small but favorable estimates of genetic correlations were obtained between HT and MARB (-0.17) and measures of tenderness represented by WBSF $(0.22)$ and TPT $(-0.25)$.

Estimates of genetic correlations between carcass traits and maturity traits of cows analyzed separately for season of measurement and age of measurement of the cow can be found in Nephawe (2003). In general, estimates of genetic correlations followed the same pattern in magnitude and directions as with overall data. Such results were not unexpected because MW, AMW, and HT measured in different seasons (summer, winter, fall and spring) or ages (4 through $8 \mathrm{yr}$ of age) seem to be basically the same trait.

\section{Implications}

Extensive data sets containing information on carcass traits of steers and mature size of paternal halfsib females were analyzed simultaneously to assess consequences of selection strategies to improve carcass merit and/or decrease mature cow size. The results show that selection for mature cow weight and/or height could be effective for changing size but would not be expected to result in much change in carcass and meat 
traits, such as percentage retail product, marbling, and tenderness. However, given the discounts presently employed in pricing carcass beef, genetic correlations of hot carcass weight with mature cow traits may be too large to ignore.

\section{Literature Cited}

BIF. 1996. Guidelines for uniform beef improvement programs. Beef Improvement Fed., Oklahoma State Univ., Stillwater.

Boldman, K. G., L. A. Kriese, L. D. Van Vleck, C. P. Van Tassell, and S. D. Kachman. 1995. A manual for USE of MTDFREML. A Set of Programs to Obtain Estimates of Variances and Covariances [DRAFT]. USDA-ARS, Washington, DC.

Choy, Y. H., J. S. Brinks, and R. M. Bourdon. 2002. Repeatabilitymeasure animal models to estimate genetic components of mature weight, hip height, and body condition score. J. Anim. Sci. 80:2071-2077.

Cundiff, L. V., K. E. Gregory, and R. M. Koch. 1998. Germplasm Evaluation in beef cattle-Cycle IV: Birth and weaning traits. J. Anim. Sci. 76:2528-2535.

Cundiff, L. V., K. E. Gregory, R. M. Koch, and G. E. Dickerson. 1969. Genetic variation in total and differential growth of carcass components in beef cattle. J. Anim. Sci. 29:233-244.

Dodenhoff, J., L. D. Van Vleck, S. D. Kachman, and R. M. Koch. 1998. Parameter estimates for direct, maternal, and grandmaternal genetic effects for birth weight and weaning weight in Hereford cattle. J. Anim. Sci. 76:2521-2527.

Fiss, C. F., and J. W. Wilton. 1992. Contribution of breed, cow weight, and milk yield to the traits of heifers and cows in four beef breeding systems. J. Anim. Sci. 70:3686-3696.

Gregory, K. E., L. V. Cundiff, and R. M. Koch. 1995. Genetic and phenotypic (co)variances for growth and carcass traits of purebred and composite populations of beef cattle. J. Anim. Sci. 73:1920-1926.

Gregory, K. E., L. V. Cundiff, G. M. Smith, D. B. Laster, and H. A. Fitzhugh, Jr. 1978. Characterization of biological types of cattle-Cycle II: I. Birth and weaning traits. J. Anim. Sci. 47:1022-1030.

Gregory, K. E., D. B. Laster, L. V. Cundiff, G. M. Smith, and R. M. Koch. 1979. Characterization of biological types of cattle-Cycle III: II. Growth rate and puberty in females. J. Anim. Sci. 49:461-471.

Johnson, D. L., and R. Thompson. 1995. Restricted maximum likelihood estimation of variance components for univariate animal models using sparse matrix techniques and average information. J. Dairy Sci. 78:449-456.

Johnston, D. J., H. Chandler, and H. U. Graser. 1996. Genetic parameters for cow weight and condition score in Angus, Hereford and Polled Hereford cattle. Aust. J. Agr. Res. 47:1251-1260.

Koch, R. M., M. E. Dikeman, D. M. Allen, M. May, J. D. Crouse, and D. R. Campion. 1976. Characterization of biological types of cattle. III. Carcass composition, quality and palatability. J. Anim. Sci. 43:48-62.

Koch, R. M., M. E. Dikeman, R. J. Lipsey, D. M. Allen, and J. D. Crouse. 1979. Characterization of biological types of cattleCycle II: III. Carcass composition, quality and palatability. J. Anim. Sci. 49:448-460.

Koch, R. M., L. V. Cundiff, and K. E. Gregory. 1982. Heritabilities and genetic, environmental and phenotypic correlations of carcass traits in a population of diverse biological types and their implications in selection programs. J. Anim. Sci. 55:1319-1329.

Koots, K. R., J. P. Gibson, C. Smith, and J. W. Wilton. 1994a. Analyses of published genetic parameter estimates for beef production traits. 1. Heritability. Anim. Breed. Abstr. 62:309-338.

Koots, K. R., J. P. Gibson, C. Smith, and J. W. Wilton. 1994b. Analyses of published genetic parameter estimates for beef production traits. 2. Phenotypic and genetic correlations. Anim. Breed. Abstr. 62:825-844.

Laster, D. B., G. M. Smith, and K. E. Gregory. 1976. Characterization of biological types of cattle. IV. Postweaning growth and puberty of heifers. J. Anim. Sci. 43:63-70.

Laster, D. B., G. M. Smith, L. V. Cundiff, and K. E. Gregory. 1979. Characterization of biological types of cattle (Cycle II). II. Postweaning growth and puberty of heifers. J. Anim. Sci. 48:500-508.

Littell, R. C., G. A. Milliken, W. W. Stroup, and R. D. Wolfinger. 1996. SAS System for Mixed Models. SAS Institute Inc., Cary, NC.

MacNeil, M. D., L. V. Cundiff, C. A. Dinkel, and R. M. Koch. 1984. Genetic correlations among sex-limited traits in beef cattle. J. Anim. Sci. 58:1171-1180.

Mohiuddin, G. 1993. Estimates of genetic and phenotypic parameters of some performance traits in beef cattle. Anim. Breed. Abstr. 61:495-522.

Morrow, G. A., and T. L. Marlowe. 1966. Genetics of mature traits in Angus cattle. J. Anim. Sci. 25:880. (Abstr.)

Nephawe, K. A. 2003. Genetic relationships between sex-specific traits in beef cattle: Mature body size of cows and carcass traits of their steer relatives. Ph.D. Diss. Univ. of Nebraska, Lincoln.

Northcutt, S. L., and D. E. Wilson. 1993. Genetic parameter estimates and expected progeny differences for mature size in Angus cattle. J. Anim. Sci. 71:1148-1153.

Pariacote, F., L. D. Van Vleck, and R. E. Hunsley. 1998. Genetic and phenotypic parameters for carcass traits of American Shorthorn beef cattle. J. Anim. Sci. 76:2584-2588.

Smith, S. P., and H. U. Graser. 1986. Estimating variance components in a class of mixed models by restricted maximum likelihood. J. Dairy Sci. 69:1156-1165.

Speer, N. C. 1993. Genetic relationships between sex-specific traits in a crossbred beef cattle population. Ph.D. Diss. Colorado State Univ., Fort Collins.

Splan, R. K., L. V. Cundiff, M. E. Dikeman, and L. D. Van Vleck. 2002. Estimates of parameters between direct and maternal genetic effects for weaning weight and direct genetic effects for carcass traits in crossbred cattle. J. Anim. Sci. 80:3107-3111.

Thallman, R. M., L. V. Cundiff, K. E. Gregory, and R. M. Koch. 1999. Germplasm evaluation in beef cattle-Cycle IV: Postweaning growth and puberty of heifers. J. Anim. Sci. 77:2651-2659.

Van Vleck, L. D., A. F. Hakim, L. V. Cundiff, R. M. Koch, J. D. Crouse, and K. G. Boldman. 1992. Estimated breeding values for meat characteristics of crossbred cattle with animal model. J. Anim. Sci. 70:363-371.

Wheeler, T. L., L. V. Cundiff, R. M. Koch, and J. D. Crouse. 1996. Characterization of biological types of cattle (Cycle IV): Carcass traits and longissimus palatability. J. Anim. Sci. 74:1023-1035.

Wilson, L. L., J. R. McCurley, J. H. Ziegler, and J. L. Watkins. 1976. Genetic parameters of live and carcass characters from progeny of Polled Hereford sires and Angus-Holstein cows. J. Anim. Sci. 43:569-576.

Woodward, B. W., E. J. Pollak, and R. L. Quaas. 1992. Parameter estimation for carcass traits including growth information of Simmental beef cattle using Restricted Maximum Likelihood with a multiple-trait model. J. Anim. Sci. 70:1098-1109. 